\title{
UTILIZAÇÃO DE TÉCNICAS DE FILMAGEM PARA OBTENÇÃ̃O DO DIÂMETRO DE BOLHAS EM COLUNA DE FLOTAÇÃO
}

\author{
A. M. R. FILHO ${ }^{1}$, G. R. L. e CARVALHO ${ }^{1}$, P. H. M. LUZ ${ }^{1}$, A. S. REIS ${ }^{1}$ e M. A. S. \\ BARROZO $^{1}$ \\ ${ }^{1}$ Universidade Federal de Uberlândia, Faculdade de Engenharia Química \\ E-mail para contato: sreis.angelica@gmail.com
}

\begin{abstract}
RESUMO - O processo de flotação é a técnica mais importante na concentração de minérios na qual a separação de partículas minerais ocorre pela adesão destas à superfície das bolhas de ar em meio aquoso. Uma das variáveis mais importantes neste processo é o controle do diâmetro das bolhas. Isto se dá a fim de aumentar o contato bolha-partícula e tornar sua captura mais eficiente. Desta forma este trabalho teve por objetivo estudar a distribuição de bolhas geradas em uma coluna de flotação a partir da passagem forçada da corrente de recirculação por um Venturi. Este método possibilita a geração de bolhas com tamanho intermediário, ou seja, com tamanho maior que as microbolhas geradas na FAD (flotação por ar dissolvido) e menor do que as bolhas geradas no sistema convencional. O diâmetro das bolhas foi monitorado por duas diferentes técnicas. A primeira consistia num sistema de filmagem estática de bolhas capturadas da coluna, através de um amostrador, uma câmera de alta velocidade e um estereomicroscópio. A segunda consistia na filmagem direta, feita a partir da captura de imagens dinâmicas da coluna pela mesma câmera. O software usado para análise das imagens foi o ImageJ. Através de condições testadas, constatouse que no amostrador as bolhas de menor diâmetro foram melhor representadas e que pela filmagem direta obteve-se mais eficiência na representação de bolhas maiores. Portanto, concluiu-se que as técnicas utilizadas são complementares e eliminam possíveis erros.
\end{abstract}

\section{INTRODUÇÃO}

O crescimento acelerado da demanda por recursos minerais não renováveis tem acarretado a exaustão das jazidas mais ricas e mais simples de serem concentradas, colocando a indústria mineral frente ao desafio de tratar minérios cada vez mais complexos. Além disso, devido à globalização da economia mundial, as unidades industriais têm sido obrigadas a produzir concentrados com especificações cada vez mais severas e custos menores (CALDARA, 2010).

Considerando esta realidade e a importância da flotação como processo de concentração de minerais, têm sido realizados esforços no sentido de desenvolver novas tecnologias e equipamentos, dentre os quais pode ser destacada a coluna de flotação. 
A flotação é a principal tecnologia aplicada para a concentração de minérios, e passou por constantes melhorias em termos de variedade e sofisticação nas últimas décadas de acordo com Somasundaran et al. (2002). A flotação é um processo físico-químico utilizado para a separação de partículas (ou agregados) minerais, pela adesão destas partículas às bolhas de ar em uma suspensão aquosa. Este processo tem como objetivo separar a(s) espécie(s) de interesse dos componentes de ganga presentes em um minério.

Segundo Ribeiro (2012), muitos autores afirmam que, no processo de flotação, a distribuição de diâmetro de bolhas é a propriedade que mais influencia na fluidodinâmica dos sistemas gás-líquido, determinando tanto o regime de escoamento quanto a área de contato para todos os fenômenos de superfície.

Rodrigues (2004) ressalta que, o diâmetro de bolha é uma variável muito importante que também influencia no rendimento e no holdup de ar (fração de gás na mistura gáslíquido). Englert (2008) ainda afirma que, um sistema com uma considerável faixa de tamanhos de bolhas (variação do diâmetro) aumenta as chances de colisão de bolha-partícula, otimizando assim o processo. Por essa razão, recentemente, a caracterização destas bolhas tem atraído a atenção de muitos pesquisadores.

Visto que a distribuição de diâmetro de bolhas é uma variável importante no processo de flotação, a determinação precisa deste parâmetro é essencial para a compreensão dos fenômenos físicos que governam estes sistemas.

Diante dos fatores citados, nota-se a importância do beneficiamento da rocha fosfática e da necessidade de uma ampla faixa de distribuição de tamanhos de bolhas para maximizar o processo de captura de partículas minerais (REIS, 2015). Desse modo, o presente trabalho teve por objetivo analisar a distribuição de diâmetros de bolhas geradas pela passagem forçada da recirculação por um Venturi a partir de dois diferentes métodos de filmagem.

\section{MATERIAIS E MÉTODOS}

\subsection{Unidade Experimental}

A unidade experimental utilizada nos experimentos, representada pela Figura 1, encontra-se no Laboratório de Sistemas Particulados da Faculdade de Engenharia Química da Universidade Federal de Uberlândia. A coluna utilizada é composta por 3 partes: um corpo cilíndrico em acrílico com $150 \mathrm{~cm}$ de comprimento e $4 \mathrm{~cm}$ de diâmetro, logo abaixo possui uma seção tronco-cônica, com $9 \mathrm{~cm}$ de altura e abaixo desta, outra seção cilíndrica com $12 \mathrm{~cm}$ de altura e $10 \mathrm{~cm}$ de diâmetro.

Através da Figura 1, pode-se observar ponto de alimentação de água (1) e coleta do concentrado (2), os pontos de recirculação em 3,4,5,6,7 os quais também são utilizados para amostragem de holdup, sistema de alimentação de ar comprimido com filtro de ar e rotâmetro em 8. É possível também identificar o Venturi (9) onde as bolhas são formadas, aerador (10) e a bomba peristáltica (11) utilizada para promover a recirculação. Na figura ainda mostra-se o ponto de coleta do rejeito (12), o sistema de amostragem de bolhas (13) e os manômetros diferenciais (14) para obtenção dos valores de holdup. 


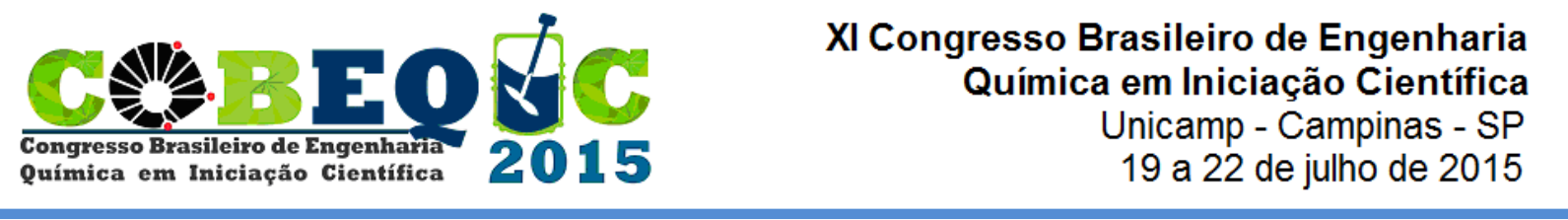

Figura 1 - Unidade experimental

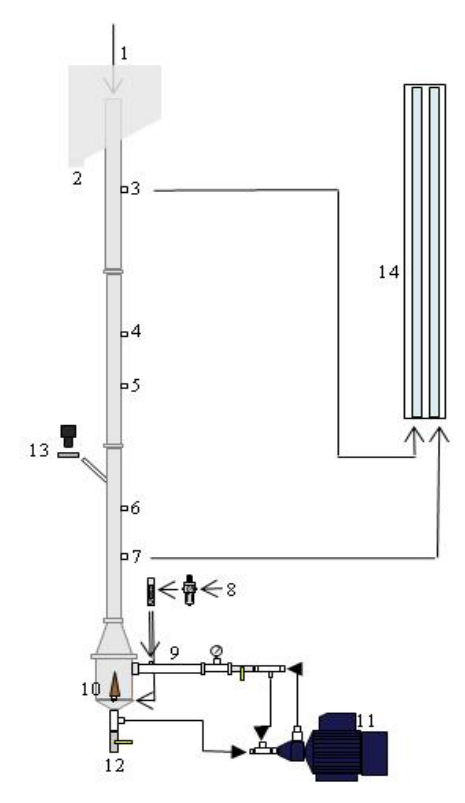

\subsection{Técnicas de Coleta de Imagem}

Para obtenção das imagens das bolhas produzidas no interior na coluna foram utilizados dois métodos diferentes, o primeiro método denominado intrusivo e o segundo denominado não-intrusivo.

No método 1 (método intrusivo) a amostragem de bolhas foi feita por meio da captura das bolhas no interior da coluna através de um amostrador projetado por Ribeiro (2012) (Figura 2). Nesse método, a coleta das bolhas foi realizada através de um tubo de aço, conectado ao amostrador, com $6 \mathrm{~cm}$ de diâmetro e $10 \mathrm{~cm}$ de comprimento posicionado no centro da coluna e com um ângulo de $45^{\circ}$ em relação à mesma. Com o auxílio de uma bomba peristáltica, posicionada à jusante do amostrador, as bolhas eram succionadas do interior da coluna com velocidade previamente controlada de forma a diminuir o efeito de quebra e coalescência das bolhas coletadas.

Figura 2 - Unidade experimental para o método 1 (método intrusivo)

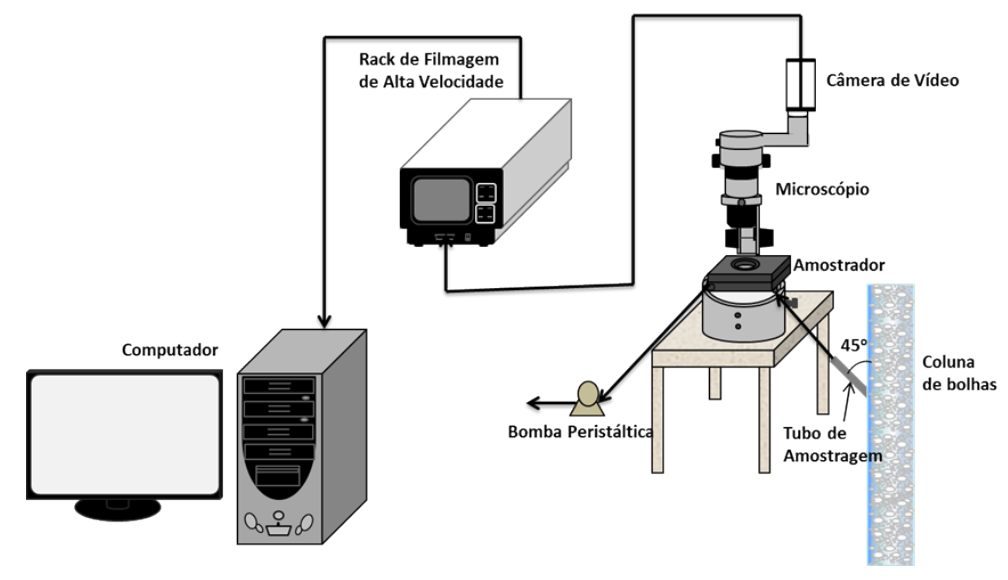


No método 2 (método não-intrusivo) as imagens foram capturadas por filmagem direta da coluna em operação com a mesma câmera de alta velocidade posicionada frente à coluna, como mostrado na Figura 3.

Como no método 2 as imagens eram obtidas pela filmagem direta através da coluna de acrílico, a deformação provocada pelo acrílico foi corrigida por meio da filmagem de 3 esferas com diâmetros conhecidos $(3,6 \mathrm{~mm}, 4,0 \mathrm{~mm}$ e 7,7 mm), colocadas no interior da coluna durante a operação.

Figura 3 - Unidade experimental para o método 2 (método não-intrusivo)

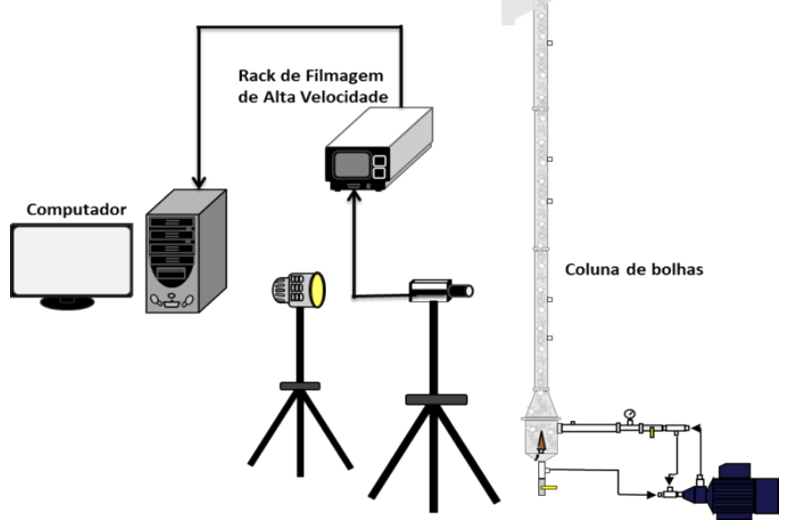

O tratamento das filmagens e imagens obtidas tanto pelo método 1 quanto pelo método 2 foi o mesmo.

\subsection{Análise do Tamanho das Bolhas}

As filmagens obtidas por ambos os métodos foram divididas em frames, por meio do software ImageGrab, que gerou as fotos utilizadas na análise das bolhas. Os diâmetros das bolhas foram determinados pelo cálculo das áreas das mesmas com o auxílio do software ImageJ, a partir de uma calibração prévia com um padrão de comprimento conhecido.

Neste segundo software, primeiramente uma calibração a partir de um padrão com comprimento conhecido era realizada o que permitia a conversão da medida encontrada de pixels para milímetros. Foram gerados histogramas com base nos diâmetros determinados com o intuito de verificar a distribuição de tamanhos de bolhas para diferentes condições de operação da coluna.

Para obtenção da distribuição de diâmetro de bolhas foram medidas em média 500 bolhas para cada condição.

\section{RESULTADOS E DISCUSSÕES}

Através das imagens obtidas foi possível verificar que as bolhas menores foram mais bem identificadas pelo método 1, visto que as bolhas maiores sofreram certa deformação e/ou eram maiores que a região abrangida na filmagem. É possível constatar a ocorrência deste fato 
ao observar a Figura 4 que contém um histograma com os dados obtidos de um teste na coluna de flotação e apresenta também uma imagem capturada por este método.

Figura 4 - Histograma com os diâmetros obtidos pelo método 1 e imagem capturada
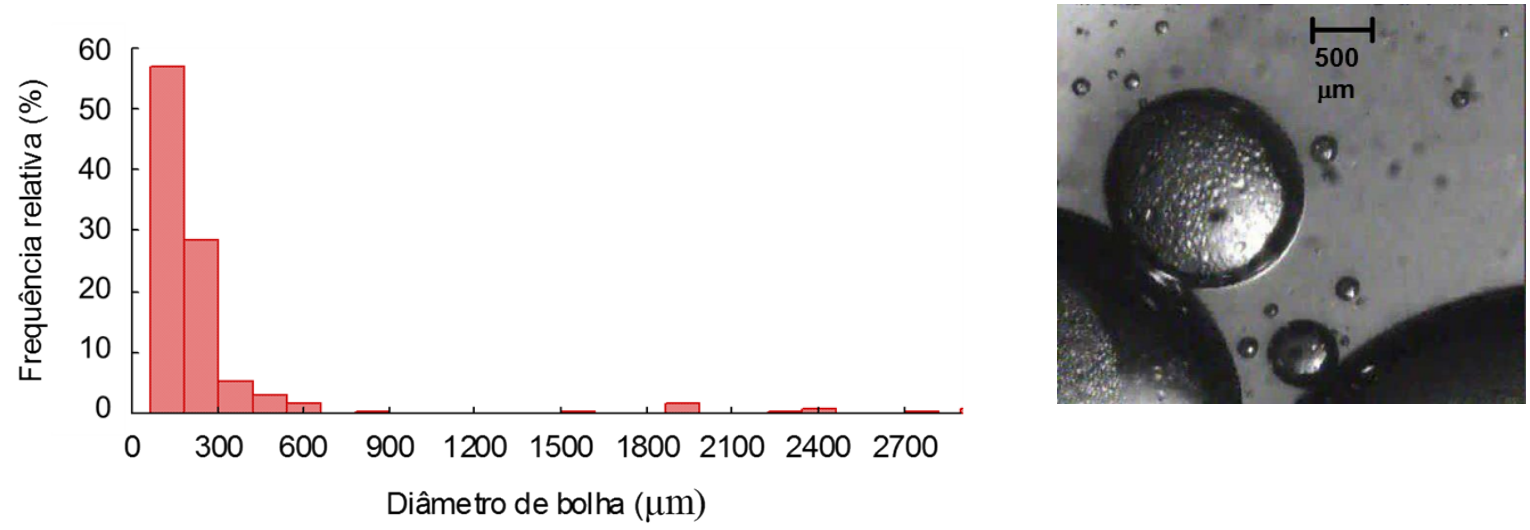

Por outro lado, o método 2 não conseguiu registrar quantidades significativas de bolhas pequenas e foi bastante eficiente na identificação de bolhas maiores. Pode-se observar esta afirmação através da Figura 5, que apresenta um histograma com dados obtidos pela filmagem direta e contém também uma imagem capturada por este método.

Figura 5 - Histograma com os diâmetros obtidos pelo método 2 e imagem capturada
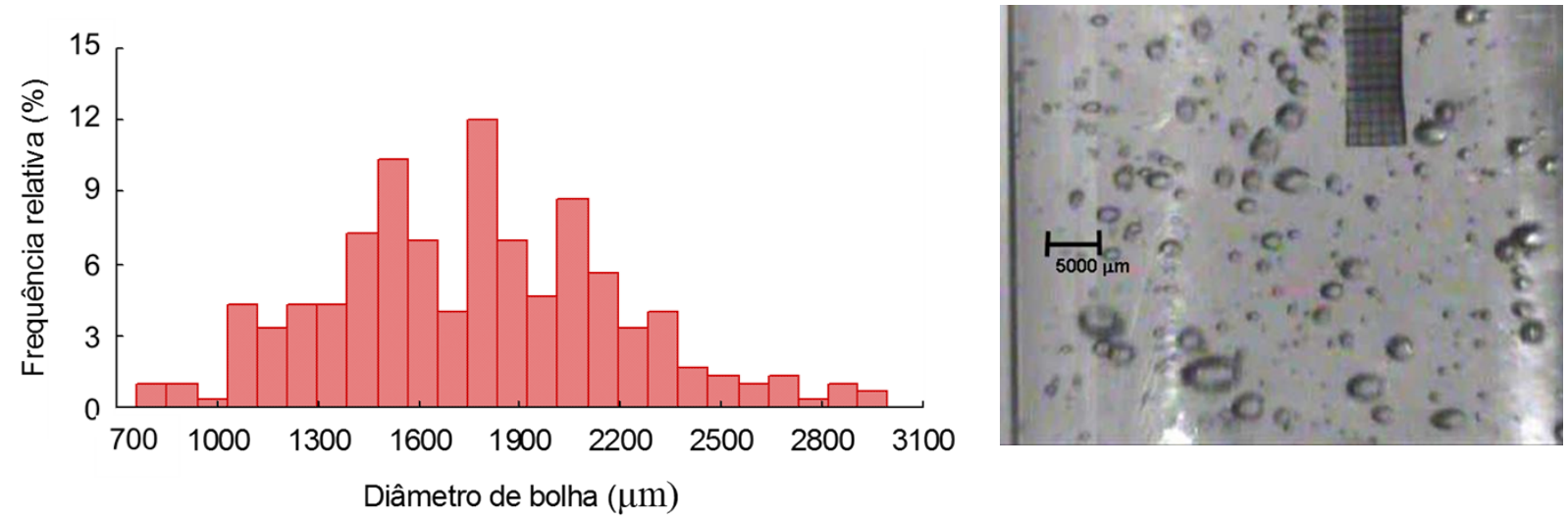

Os dados dos histogramas são do mesmo teste. Desta forma, percebe-se a presença de bolhas pequenas, intermediárias e grandes, no interior da coluna de flotação, e que as duas técnicas são necessárias para a análise completa do diâmetro de bolhas.

\section{CONCLUSÃO}

Durante a operação da coluna era possível se verificar a olho nu a ampla variância na distribuição das bolhas geradas em seu interior, justificando assim a utilização de dois 


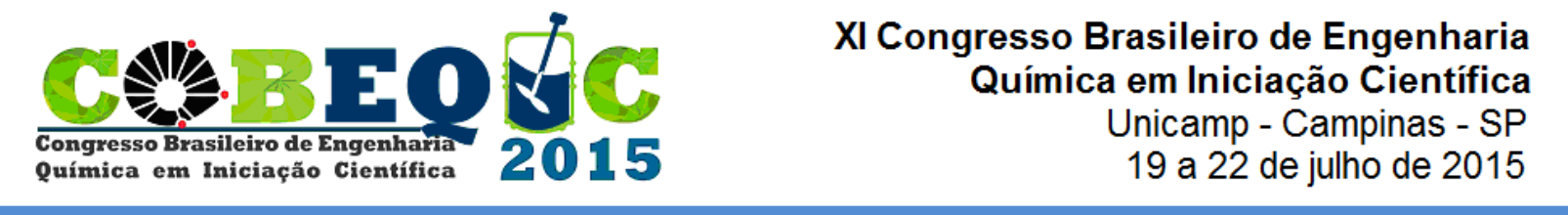

métodos específicos na coleta das imagens, sendo que esses métodos se mostraram eficientes e complementares para se obter a distribuição total do tamanho das bolhas produzidas em diversas condições experimentais.

Através do plano coordenado de experimentos realizados e da análise das imagens obtidas pelos dois métodos de amostragem entende-se que, o método 1 (intrusivo), se mostrou mais eficaz para análise de bolhas de menor diâmetro, enquanto o método 2 (filmagem direta) para as bolhas maiores. Esse fato é observado para situações com menores vazões de ar sendo os métodos complementares, já para condições em que a vazão de ar é maior percebeu-se que a utilização do segundo método serviu como validação para o primeiro já que as distribuições encontradas foram coincidentes.

\section{REFERÊNCIAS BIBLIOGRÁFICAS}

CALDARA, J. A.; CORREA, J. C. G. Abordagem sobre a aplicação da flotação em coluna em beneficiamento mineral. Jornada Giulio Massarani de Iniciação Científica, Artística e Cultural - UFRJ, 2010.

ENGLERT, A. H. Flotação por ar dissolvido (FAD) de micropartículas, caracterização de microbolhas e medidas de força de interação bolha-partícula. Tese (Doutorado em Engenharia de Minas), Universidade Federal do Rio Grande do Sul, Porto Alegre, RS, 2008 .

REIS, A. S. Estudo da geração de bolhas de diversos tamanhos em coluna de flotação. Tese (Mestrado em Engenharia Química), Universidade Federal de Uberlândia, Uberlândia, MG, 2015.

RIBEIRO, J. A. Contribuição ao estudo experimental e em CFD da fluidodinâmica de colunas de bolhas com aplicações na separação de misturas oleosas e processamento mineral por ar dissolvido, Tese (Doutorado em Engenharia Química), Universidade Federal de Uberlândia, Uberlândia, MG, 2012.

RODRIGUES, R. T. Desenvolvimento da técnica LTM-BSizer para a caracterização de bolhas e avaliação de parâmetros no processo de flotação. Tese (Doutorado em Engenharia de Minas), Universidade Federal do Rio Grande do Sul, Porto Alegre, RS, 2004.

SANTANA, R.C. Análise da Influência do Tamanho da Partícula na Flotação de Apatita em Coluna. Dissertação (Mestrado em Engenharia de Minas), Faculdade de Engenharia Química - UFU. Uberlândia, 2007.

SOMASUNDARAN P.; CHANG, P.; SHALL R.; DAHL, B. Beneficiation os phosfhates: Fundamentals and Technology, 2002.

\section{AGRADECIMENTOS}

Agradecimentos especiais à Capes e ao CNPq, como órgãos de fomento da pesquisa e à Faculdade de Engenharia Química da Universidade Federal de Uberlândia pelo incentivo e apoio à realização deste trabalho. 